\title{
خैFermilab
}

Managed by Fermi Research Alliance, LLC for the U.S. Department of Energy Office of Science

\section{Pressurized Gas Beam Monitor for Extremely High Intensities - Phase II}

\section{Cooperative Research and Development Agreement Final Report}

CRADA Number: FRA-2016-0029

Fermilab Technical Contact: Katsuya Yonehara

\section{Work Performed under STTR grant DE-SC0013764 With Muons, Inc.}

Summary Report

16 April 2020

This manuscript has been authored by Fermi Research Alliance, LLC under Contract No. DE-AC02-07CH11359 with the U.S. Department of Energy, Office of Science, Office of High Energy Physics. 


\section{NOTICE}

This report was prepared as an account of work sponsored by an agency of the United States government. Neither the United States government nor any agency thereof, nor any of their employees, makes any warranty, express or implied, or assumes any legal liability or responsibility for the accuracy, completeness, or usefulness of any information, apparatus, product, or process disclosed, or represents that its use would not infringe privately owned rights. Reference herein to any specific commercial product, process, or service by trade name, trademark, manufacturer, or otherwise does not necessarily constitute or imply its endorsement, recommendation, or favoring by the United States government or any agency thereof. The views and opinions of authors expressed herein do not necessarily state or reflect those of the United States government or any agency thereof.

Available electronically at http://www.osti.gov/bridge

Available for a processing fee to U.S. Department of Energy and its contractors, in paper, from: U.S. Department of Energy Office of Scientific and Technical Information P.O. Box 62

Oak Ridge, TN 37831-0062

phone: 865.576 .8401

fax: 865.576 .5728

email: mailto:reports@adonis.osti.gov

Available for sale to the public, in paper, from:

U.S. Department of Commerce

National Technical Information Service

5285 Port Royal Road

Springfield, VA 22161

phone: 800.553.6847

fax: 703.605.6900

email: orders@ntis.fedworld.gov

online ordering: http://www.ntis.gov/ordering.htm 
In accordance with Requirements set forth in Article X of the CRADA, this document is the final CRADA report, including a list of Subject Inventions, to be forwarded to the Office of Science and Technical Information as part of the commitment to the public to demonstrate results of federally funded research.

CRADA number:

CRADA Title:
FRA-2016-0029

Pressurized Gas Beam Monitor for Extremely High Intensities Phase II

Parties to the Agreement: MuPlus, Inc. and Fermi Research Alliance, LLC

\section{Abstract of CRADA work:}

A novel pressurized gas-filled multi-RF-cavity beam profile monitor has been studied that is simple and robust in high-radiation environments. Charged particles passing through each RFcavity in the monitor produce intensity-dependent ionized plasma, which changes the gas permittivity. Standard RF techniques to measure the change in quality factor $(Q)$ and frequency (f) as a function of time are then used to determine the change in permittivity and corresponding beam intensity in each cavity in the profile monitor. The sensitivity to beam intensity is adjustable using gas pressure and RF gradient. The performance of the gas-filled beam profile monitor has been numerically simulated to evaluate the sensitivity of permittivity measurements and the effectiveness of calibration strategies. An entire multi-RF-cavity system has been designed and a demonstration test has been prepared. 


\section{Summary of Research Results:}

In Phase I the following studies were undertaken:

The performance of a gas-filled RF cavity was numerically simulated to evaluate the sensitivity of permittivity measurements and the effectiveness of calibration strategies:

- The fundamental processes in the production of ions when a beam of ions passes through a gas

- Simulations of beam particles passing through a gas RF cavity

- Simulations of frequency shift in a RF cavity as a function of beam position -shown in Figure 5.

- Studies of RF energy consumption by the RF cavity as a function of beam position to determine position measurement sensitivity -shown in Figure 4.

- Studies of addition of electronegative dopants to the gas and their effects on mobility of the heavy ions in the RF cavity -shown in Fig. 7 and 8.

- Simulated beam profiles after the LBNF target, including secondary particles produced

- Simulation of LBNF conditions, such as low primary beam energy, long target and empty target -shown in Fig. 4 and 6. The range covers the expected beam intensities in NuMI and LBNF.

An RF cavity-beam profile system was conceived with corresponding subsystem demonstration tests:

- including the RF source, waveguide, and data acquisition system -descriptions given above in this narrative

- experimental plans to utilize intense beam facilities, MTA, FTBF and NuMI at Fermilab -descriptions is given above in this narrative and below in the Phase II plans.

In addition, we presented the first evaluation of this novel hadron monitor at IPAC 2015. We also plan to publish the results of phase I in a technical note at Fermilab.

Most of the essential concepts for the behavior of beams in pressurized gas, including the use of dopants to control the beam dynamics, were studied in previous studies in the MTA. This Phase I project has verified that these concepts, which were invented and developed as a technique for cooling muon beams, can be extended to create a robust beam profile monitor with the range and sensitivity needed for LBNF and other places where radiation tolerance is important.

\section{In Phase II the following tasks were undertaken:}

\section{The Experiment}

We built a RF test detector (Figure 1), to validate the concept of beam detection in the RF detector developed in Phase I. A schematic of the electronics we assembled for the beam tests is illustrated in Figure 2. We used a network analyzer (NWA) as a RF power source which generates RF power in the 
range from 0 to $20 \mathrm{dBm}$. The RF signal is sent through a long $1 / 2$ '” heliax cable (labeled Orange). The detector was installed in front of the Main Injector beam dump.

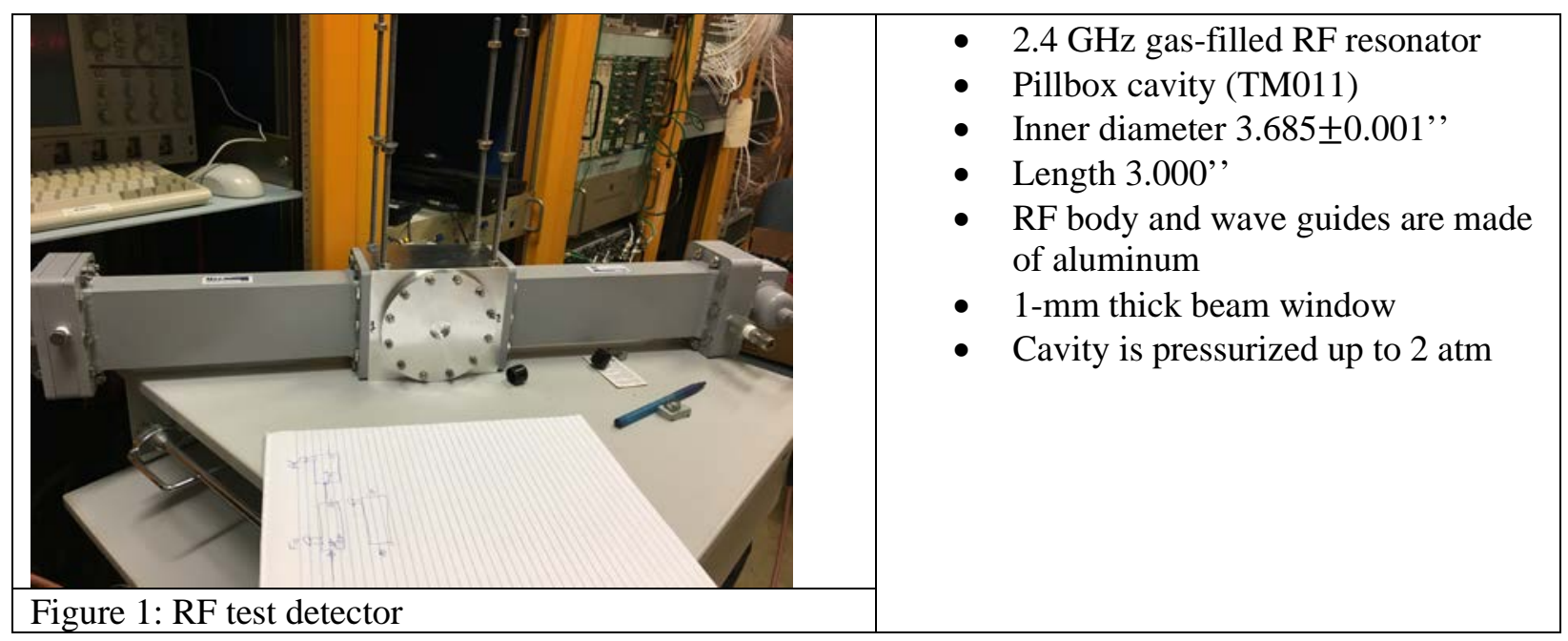

\begin{tabular}{ll|l|}
\hline $\begin{array}{l}\text { Real-time } \\
\text { RF power meter } \\
\text { Figure 2: Electronics of RF detector for the beam } \\
\text { test. }\end{array}$ & $\begin{array}{l}\text { Figure 3: Observed RF gain. Blue is taken at the } \\
\text { driving frequency 2.385 GHz (nominal), Orange } \\
\text { and green are taken at 2.390 and 2.379 GHz, } \\
\text { respectively. }\end{array}$ \\
\hline
\end{tabular}

\section{The Analysis}

Figure 3 shows the typical beam event in the RF test detector for the demonstration test. The beam is a single batched beam. We observed that the beam batch intensity went down by $20 \%$ in the single spill. The MI experts confirmed this is real.

Figure 4 shows the estimated RF power consumption in the RF test detector at the equilibrium voltage by using equation. The plot suggests that the atmospheric N2 gas (blue point) is the most sensitive to the beam intensity. The deviation of point from the fitting curve is at most 10 $\%$ level. The error can be improved by adding a correction. 

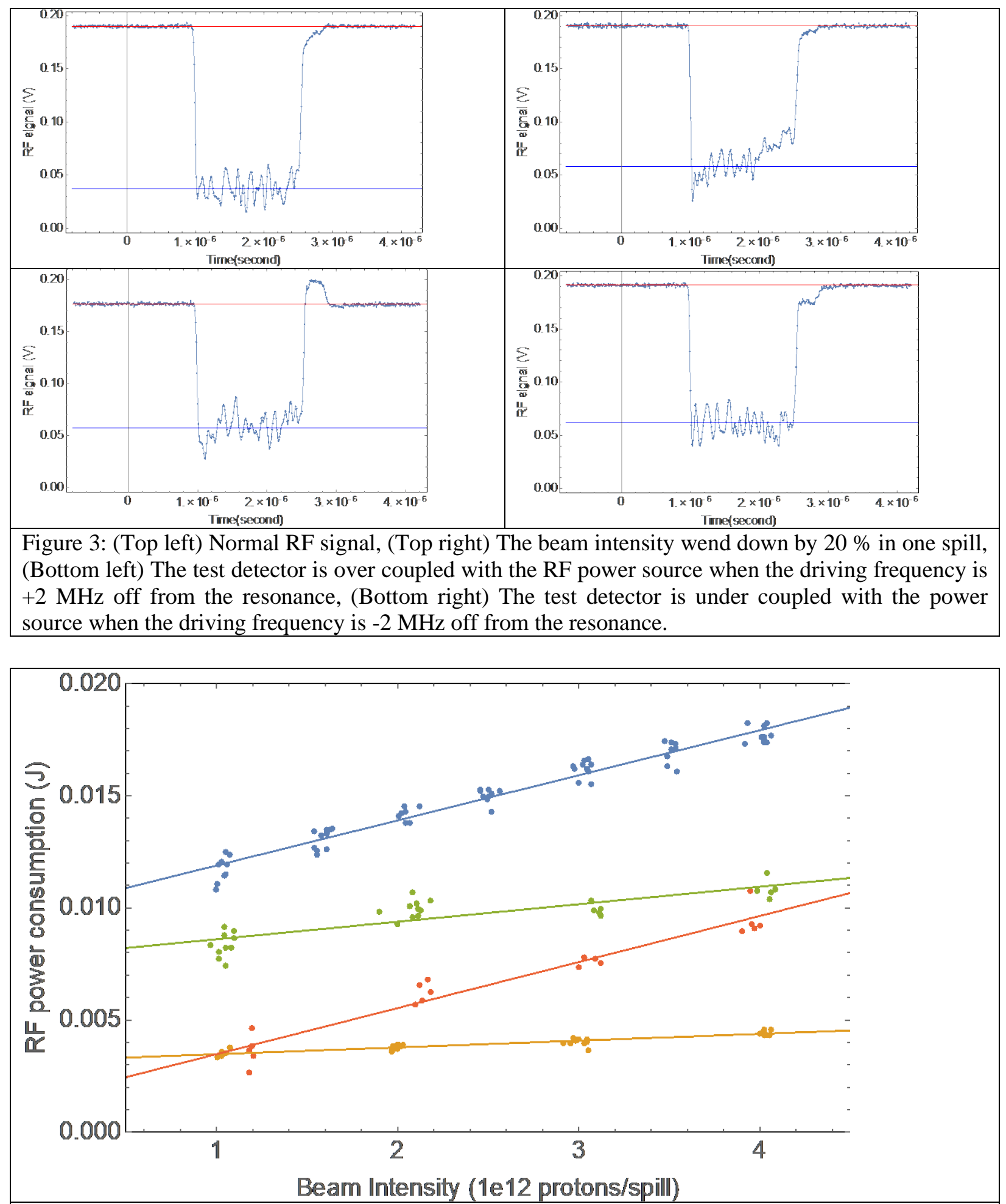

Figure 4: Estimated RF power consumption in the RF test detector. Blue is taken with atmospheric N2 gas $\left(V_{0}=120 \mathrm{~V}\right)$, orange is taken with 2-atm N2 gas $\left(V_{0}=60 \mathrm{~V}\right)$, green is tanek with 2-atm dry air $\left(V_{0}=120 \mathrm{~V}\right)$, and red is taken with 1-atm He gas $\left(V_{0}=120 \mathrm{~V}\right)$. 
The measurement shows a good linearity of RF signal with respect to the beam intensity. We tested N2, He, and dry air and the atmospheric N2 gas shows the best sensitivity in the range of $1 \mathrm{e} 12$ to $4 \mathrm{e} 12$ protons per spill. However, we see the deviation of data points, at most $10 \%$ level. There are several sources of the fraction for each group. The beam intensity is varied in the beam spill. Figure 7 shows the example. We estimated the equilibrium potential from the first 1 osec beam. This makes 5-10\% fraction of the estimated beam signal. This event suggests that the $\mathrm{RF}$ detector is sensitive to the time structure of incident beam.

In summary, We carried out the beam demonstration test of the novel RF detector and found a good linearity of the RF response with respect to the beam intensity. We validated the concept of RF beam detector.

\section{Related Reports, Publications, and Presentations:}

K. Yonehara, M.A. Cummings, R.P. Johnson, “Gas Filled RF Resonator Hadron Beam Monitor for Intense Neutrino Beam Experiments", 8th International Conference on High Energy Physics, Chicago, USA, 2016. https://pos.sissa.it/282/1211/pdf

K. Yonehara, et al, "Progress Of Gas-Filled Multi-Rf-Cavity Beam Profile Monitor For Intense Neutrino Beams", Proceedings of NAPAC2016, Chicago, IL, USA, 2016. http://accelconf.web.cern.ch/AccelConf/napac2016/papers/fra1co05.pdf

K. Yonehara et al., "R\&D of a Gas-Filled RF Beam Profile Monitor for Intense Neutrino Beam Experiments", in Proc. 8th Int. Particle Accelerator Conf. (IPAC'17), Copenhagen, Denmark, May 2017, pp. 491-493. doi:10.18429/JACoW-IPAC2017-MOPAB153

\section{Subject Inventions listing:}

$\mathrm{N} / \mathrm{A}$

Report Date: 16 April 2020

Technical Contact at Fermilab: Katsuya Yonehara

This document contains NO confidential, protectable or proprietary information. 